\title{
O MODELO POLICIAL PROFISSIONAL E A FORMAÇÃO PROFISSIONAL DO FUTURO POLICIAL NAS ACADEMIAS DE POLÍCIA DO ESTADO DO RIO DE JANEIRO ${ }^{1}$
}

\author{
Paula Poncioni*
}

\begin{abstract}
Resumo: No Brasil, um exame da questão da segurança pública revela que, pelo menos desde meados dos anos 70 , há um crescimento contínuo da criminalidade e da violência, principalmente nas regiões metropolitanas e periferias das grandes cidades do País, e que o sistema judiciário e, em particular, a polícia tem se mostrado ineficaz para o enfrentamento da questão. Neste cenário, um dos temas freqüentemente levantados por estudiosos da área de segurança, por formuladores de políticas públicas, por autoridades de governo e pelos próprios policiais é a necessidade de profissionalizar a polícia brasileira como um recurso para capacitá-la para o desempenho mais eficiente, mais responsável e mais efetivo na condução da ordem e segurança públicas. O objetivo principal deste trabalho é analisar o modelo de polícia profissional presente no ensino e treinamento profissional desenvolvido nas academias de polícia, civil e militar, e suas conseqüências para a formação do futuro policial, com vistas ao desempenho das atividades policiais cotidianas. A análise aqui proposta baseia-se, fundamentalmente, na documentação relativa aos currículos dos cursos de formação profissional básica ministrados pelos centros de ensino e treinamento profissional - civil e militar do Estado do Rio de Janeiro: a Academia Estadual Sylvio Terra (ACADEPOL); o Centro de Formação e Aperfeiçoamento de Praças 31 de Voluntários (CFAP); e a Academia de Polícia D. João VI (APM D. João VI).
\end{abstract}

* Professora adjunta do Departamento de Política Social e Serviço Social Aplicado da Escola de Serviço Social da Universidade Federal do Rio de Janeiro; doutora em Sociologia. E-mail: pponcioni@terra.com.br

Artigo recebido em 7 jul. 2005; aprovado em 21 nov. 2005. 


\section{Introdução}

No Brasil, um exame, ainda que superficial, da questão da segurança pública revela que, pelo menos desde meados dos anos 70, há um crescimento contínuo da criminalidade e da violência, principalmente nas regiões metropolitanas e periferias das grandes cidades do país, e que o sistema judiciário, e, em particular, a polícia tem se mostrado ineficaz para o enfrentamento da questão.

Especialmente nas áreas urbanas do país, a sensação de medo e insegurança - objetiva e subjetiva - tem sido experimentada como um grave problema público devido à expectativa de que qualquer pessoa pode se tornar vítima de crime em qualquer ponto das cidades e em qualquer momento de sua vida cotidiana.

Neste cenário caótico de insegurança, um dos temas frequientemente levantados por estudiosos da área de segurança, por formuladores de políticas públicas, por autoridades de governo e pelos próprios policiais é a necessidade de profissionalizar a polícia brasileira como um recurso para capacitá-la para o desempenho mais eficiente, mais responsável e mais efetivo na condução da ordem e segurança públicas.

Não obstante nas últimas duas décadas terem se verificado inovações na área da formação profissional, poucas iniciativas lograram sucesso no sentido de implementar mudanças efetivas nas práticas e procedimentos dominantes, inscritos em um padrão de desempenho que se traduz não só na ineficácia dos resultados obtidos para o enfrentamento da questão, mas que se reveste de aspectos suplementares relacionados, fundamentalmente, à forma de atuação predominantemente violenta e arbitrária da polícia, permanecendo como desafio à sociedade contemporânea brasileira. Salvo raríssimas exceções, as propostas para reformulação da formação profissional da polícia no país, não incorporaram o debate sobre o modelo profissional a ser adotado pela polícia e as metodologias práticas de intervenção para a realização das tarefas cotidianas envolvendo a manutenção da ordem e segurança públicas. 
Particularmente, no Estado do Rio de Janeiro, constata-se que a urgência de respostas imediatas às demandas e pressões para maior segurança tem sido o fio condutor para a implementação de propostas variadas, muitas vezes divergentes entre si, para a área de segurança pública, em particular para a formação profissional, em ambas organizações policiais, sem que, até o momento, tenham sido alcançadas mudanças mais efetivas, de longo e duradouro espectro no manejo das questões relativas ao controle do crime mais eficaz e responsável. ${ }^{2}$

Neste sentido, entende-se que é de fundamental importância para as intervenções que visem à efetividade do trabalho policial, considerar o exame dos modelos policiais profissionais existentes, suas premissas para a conduta policial, os objetivos visados, os meios utilizados para alcançá-los e as consequiências para o exercício da atividade policial na contemporaneidade.

O objetivo principal deste trabalho é analisar o modelo de polícia profissional presente no ensino e treinamento profissional desenvolvido nas academias de polícia, civil e militar, e suas conseqüências para a formação do futuro policial, com vistas ao desempenho das atividades policiais cotidianas na sociedade brasileira de hoje.

A análise aqui proposta baseia-se, essencialmente, na documentação relativa aos currículos dos cursos de formação profissional básica ministrados pelos centros de ensino e treinamento profissional - civil e militar - do Estado do Rio de Janeiro: a Academia Estadual Sylvio Terra (ACADEPOL), onde são realizados o recrutamento, a seleção, a formação, a especialização, e o aperfeiçoamento profissional de policiais civis - agentes policiais e delegados de polícia; o Centro de Formação e Aperfeiçoamento de Praças 31 de Voluntários (CFAP), responsável pela formação e aperfeiçoamento profissional de praças; e a Academia de Polícia D. João VI (APM D. João VI), onde é realizado o curso de formação profissional de oficiais. 


\section{Premissas e consequiências de um modelo policial profissional na formação profissional do futuro policial para o desempenho das atividades cotidianas}

$\mathrm{Na}$ organização policial, geralmente, a primeira etapa da socialização do futuro policial se dá através da academia de polícia, onde se opera formalmente a socialização secundária dos "novatos", com a introdução de conhecimentos e habilidades técnicas. A segunda etapa se realiza nos locais e nas posições designadas para o policial trabalhar, e a aprendizagem ocorre, privilegiadamente, a partir da realidade cotidiana da organização policial. ${ }^{3}$

Nas academias de polícia, usualmente, o conteúdo de um processo formal de socialização profissional para "moldar" os futuros policiais inclui a seleção de certas matérias teóricas e práticas e de determinados eventos sobre outros, uma posição estilizada para as atividades rotineiras do cargo a ser ocupado, e algumas idéias da conveniência de um elenco de respostas comportamentais para situações periódicas no mundo do trabalho.

Nesta perspectiva, os programas de ensino e treinamento profissional dos policiais nas academias de polícia exemplificam uma das estratégias fundamentais de transmissão de idéias, conhecimentos e práticas de uma dada visão do papel, da missão, do mandato e da ação deste campo profissional, que necessariamente envolve a transmissão de valores, crenças e pressupostos sobre este campo específico e que é revelada, particularmente, nas diretrizes teóricas e metodológicas dos currículos dos cursos oferecidos para a socialização do novo membro, em um contexto sócio-histórico determinado.

Portanto, destaca-se a importância da formação profissional básica realizada nas academias de polícia para a construção da identidade profissional, fundamentalmente, como uma etapa que faz considerável diferença para a vida profissional do policial, não apenas dada a importância da experiência de formação do membro na aquisição formal dos valores e normas próprias da profissão e das competências e das habilidades para o campo de trabalho, mas 
também na aquisição dos valores e crenças acerca da profissão, consubstanciados em uma base de conhecimento e de cultura comum sobre o que é ser policial em um determinado modelo de polícia profissional.

$\mathrm{Na}$ literatura especializada produzida pelas ciências sociais, pode-se encontrar uma enorme quantidade de modelos atribuídos à polícia: modelo "paramilitar", "burocrático-militar", modelo de aplicação da lei ("law enforcement"), modelo de "serviço", modelo de "polícia comunitária" ("community policing”), entre outros.

Vale salientar que não há modelos policiais puros, unidimensionais, como também não há práticas policiais genuínas e que envolvam uma só dimensão. Um modelo constitui um quadro de referência analítico, que apresenta um conjunto coeso de argumentos acerca do papel, das funções e da missão da polícia, da filosofia de trabalho, da política administrativa adotada e das estratégias e táticas operacionais concebidas pela organização para moldar o comportamento policial numa determinada sociedade, num dado momento histórico.

No percurso da história da polícia, evidencia-se, sobremaneira, que os aspectos vinculados à burocratização e à militarização, com excessivo realce no comportamento profissional e legalista dos policiais, permearam a construção de um determinado modelo policial profissional, que ainda hoje serve de base para a estrutura policial nas sociedades democráticas ocidentais, orientando a organização da polícia, os seus princípios e métodos, desde a aplicação do treinamento, englobando desde a filosofia, a terminologia, a literatura organizacional até o estilo de policiamento, envolvendo táticas e estratégias, o equipamento utilizado nas operações de policiamento, etc.

É importante reconhecer que esse modelo policial profissional, proveniente das reformas da polícia que ocorrem no final do século XIX e durante a primeira metade do século XX, é uma resposta inovadora para os problemas que precederam sua montagem e a sua peculiaridade reside no entrelaçamento de dois modelos de polícia - 
o burocrático-militar e o de aplicação da lei. De modo geral, sua implementação traz consigo a expectativa dos reformadores de tornála mais disciplinada, menos discricionária nas suas operações, menos politizada e mais profissional.

De acordo com esse modelo, o policial é um aplicador imparcial da lei, relacionando-se com os cidadãos profissionalmente, em condições neutras e distantes, cabendo-lhe cumprir os deveres oficiais, seguindo os procedimentos rotinizados, independentemente de inclinações pessoais e a despeito das necessidades do público não enquadradas pela lei. As atividades que deslocam a polícia para resolver outros tipos de problemas da comunidade, e requerem outros tipos de resposta, são identificados como "assistência social", e são objeto de desprezo - "garbage calls" (Moore, 1992, p. 115). Toda ação policial deve ser explicada por meio da referência à legalidade e os policiais são encorajados a controlar situações comuns como se fossem questões de aplicação da lei, ao invés de manutenção de ordem. Com a ênfase no controle do crime, os policiais são pressionados a "produzir" prisões e multas, sendo esperado que façam seu trabalho usando a lei para punir aqueles compreendidos como merecedores.

Nesse modelo, a organização policial espera por um crime, a ser notificado por alguém, para ativar seu trabalho, em resposta ao que é demandado como serviço. Em conseqüência, a polícia se estrutura como uma "máquina de reação" forte (Fielding, 1996, p. 44), que utiliza regras e procedimentos estipulados por critérios próprios, uma vez ativada pelo público, em uma perspectiva claramente reativa.

Com o gradual aumento do crime violento na maior parte das grandes cidades dos países das democracias ocidentais, o discurso do "controle do crime" é progressivamente substituído pelo da "guerra contra o crime", fortalecendo no imaginário do público e da polícia a idéia do perigo iminente e da necessidade de mobilização máxima de esforços para derrotar aquilo que provoca tal circunstância.

Neste contexto, a adoção de um estilo militar de organização não se dá por acaso, mas retrata a tentativa de estruturar um arranjo 
organizacional que possa mobilizar os indivíduos para reagir, dentro de uma maneira aderente e disciplinada, a fim de responder imediatamente às situações apresentadas. Nesta espécie de missão de combate contra o crime, o modelo de prontidão militar mostra-se como aquele capaz, por excelência, para complementar de maneira, supostamente mais eficiente a ação da polícia, com vistas a controlar o crime.

A esse modelo de polícia profissional que reforça os aspectos legalistas do trabalho policial, em um arranjo burocrático-militar, com ênfase no controle do crime, como a alternativa primordial para lidar com o assunto de segurança pública, denominei de "modelo de polícia profissional tradicional" (Poncioni, 2004).

A polícia, orientada principalmente para o controle do crime, com forte apelo ao "combate ao crime", tem a grande vantagem de fornecer o que é percebido amplamente pelo público e pelos próprios policiais como a missão das instituições policiais. No entanto, a ênfase no controle do crime conduz ao descuido de outras demandas e interesses; ademais, esta concepção baseada em uma estratégia exclusivamente reativa, mostra-se ser menos efetiva que o prometido com relação ao controle do crime em geral e, em pelo menos alguns crimes particulares, o seu fracasso é amplamente indicado na literatura. ${ }^{4}$ Além disso, como argumenta Fairchild (1984), a idéia de "lei e ordem" compreende não somente o cumprimento de lei, mas também a manutenção da ordem em situações diversas de intranquiilidade civil ou de catástrofe. Acrescente-se, ainda, que muitos estudos sociológicos de língua anglo-saxã têm revelado uma multiplicidade de tarefas exercidas no trabalho diário do policial que nem sempre estão relacionadas ao atendimento a problemas estritamente legais ou penais, revelando um cotidiano que tem pouco, ou quase nada, a ver com os aspectos propagados em torno da restrita idéia do trabalho policial vinculado apenas ao cumprimento da lei.

Assim, é possível inferir que a despeito do incontestável avanço que significou a organização do trabalho policial sob os auspícios 
desse modelo policial profissional, são várias as conseqüências indesejáveis decorrentes dos princípios emanados pelo modelo. ${ }^{5}$

No que diz respeito, especificamente, à formação profissional do policial, pode-se apontar uma primeira importante conseqüência resultante do modelo profissional em foco - o descompasso entre o conhecimento adquirido para o desempenho do trabalho policial nos bancos das academias e a realidade na qual se realiza o trabalho cotidiano da polícia. De um lado, dentro da organização, principalmente no período de treinamento, transmite-se a idéia do trabalho policial baseado essencialmente no controle do crime e no cumprimento da lei, com ênfase na importância de sua adesão às regras e procedimentos da organização para o controle do crime nos limites da lei. Além disso, neste contexto, ele experimenta uma enorme restrição com relação à tomada de decisão nas atividades concernentes ao dia-a-dia da organização. De outro, fora da organização, ele se defronta com uma grande diversidade de situações com relação às quais tem de tomar constantemente decisões que não estão necessariamente de acordo com as diretrizes, procedimentos, ordens gerais, ou mesmo com os processos formais da legalidade, mas têm por objetivo fundamentalmente a aplicação eficiente de certas leis e regras para a manutenção da ordem, muito mais do que o respeito integral à legalidade ou às regras estabelecidas pela organização. ${ }^{6}$

Deste modo, a formação e treinamento profissional fornecidos nas academias de polícia, quase sempre atados rigorosamente aos aspectos normativo-legais do trabalho, acabam sendo simplistas e irreais, levando o indivíduo a descartar o que foi ensinado na academia nesta fase de socialização. ${ }^{7}$

$\mathrm{Na}$ história recente, a partir dos anos 70, em diferentes contextos nacionais, o reconhecimento de algumas das limitações deste modelo, dotou o profissionalismo entre as polícias de uma nova direção, com a adoção de um novo tipo de modelo de polícia profissional que enfatiza o serviço público, a discrição do policial informada por alto nível de educação e treinamento, e a ligação mais estreita entre a polícia e a comunidade. 
Verifica-se que as mudanças propostas para a polícia são pensadas tanto em termos da posição do policial na organização moldada sob o modelo quasi-militar - com sua insistência no cerceamento de discrição, falta de recompensas para iniciativas individuais fora dos rígidos parâmetros de disciplina e hierarquia, e impessoalidade em geral - quanto em termos da necessidade de diminuir o isolamento da polícia em relação ao público.

Ressalta-se, porém, que este deslocamento do profissionalismo na polícia não pode ser tomado como homogêneo em suas premissas, como também não pode ser generalizado para todos os países ocidentais como, por exemplo, o Brasil.

No caso brasileiro, a formação profissional sob os auspícios do modelo policial profissional desenvolvido nas academias de polícia mostra-se particularmente problemático, não apenas pela ineficácia das atividades para reduzir o crescimento da criminalidade e da violência, o que Levy (1997) chamou de "crise do modelo liberal de organização policial", mas reveste-se de contornos peculiares, que insinuam extensos obstáculos para o estabelecimento das bases do que denomino o "modelo de polícia profissional novo", identificado com as premissas mencionadas acima.

\section{A versão "carioca" do modelo policial profissional e a formação profissional do policial nas academias de polícia ${ }^{8}$}

A pesquisa desenvolvida junto à Polícia Civil e à Polícia Militar do Estado do Rio de Janeiro ${ }^{9}$ destaca a especificidade que envolve a polícia brasileira, traduzida na duplicidade das polícias para o desempenho das funções de manutenção da ordem e aplicação da lei. Neste sentido, pode-se afirmar que a organização policial civil e a organização policial militar constituem-se dois universos distintos, no que diz respeito às funções, às estruturas organizacionais, aos sistemas de carreira, e à formação profissional. 
No entanto, o estudo salienta, ainda, que, apesar de incomparáveis em determinados aspectos, como os acima mencionados, a Polícia Civil e a Polícia Militar podem ser equiparadas no que tange à alocação de meios governamentais para dotar de melhores recursos humanos a polícia do Estado.

Verificam-se fragilidades comuns no processo de socialização do futuro policial, uma vez enfocados alguns indicadores objetivos concebidos como essenciais para qualificar uma polícia como profissionalizada, como, por exemplo, um rigoroso sistema de recrutamento e seleção de recursos humanos, ou mesmo a estruturação dos cursos de formação profissional.

A pesquisa realizada nos centros de ensino e treinamento profissional da Polícia Civil e da Polícia Militar do Estado do Rio de Janeiro indica que os tipos de conhecimentos aprendidos durante o período de formação profissional incluem as várias dimensões de conhecimento da cultura organizacional, de conhecimento técnico básico e de procedimentos rotineiros do "fazer profissional", com ênfases diferenciadas para cada nível hierárquico.

O estudo aponta, porém, que entre a organização policial civil e a organização policial militar há dramáticas variações no processo de formação de seus membros, relacionadas, em especial, ao grau de intensidade conferido ao ensino e treinamento profissional básico dos recém-admitidos.

Neste sentido, observa-se a profunda distinção entre aquele que planeja e aquele que executa, permeando todo o cotidiano da organização policial, afetando por inteiro o funcionamento e a estruturação da formação profissional do policial.

$\mathrm{O}$ aspecto mais visível desta concepção de organização do trabalho manifesta-se no interior da organização policial militar, residindo na rígida divisão que separa hierarquicamente o ambiente organizacional pelas funções, responsabilidades e papéis conferidos aos Oficiais, preparados para exercerem as atividades de 
planejamento, e aquelas atribuídas aos Praças, preparados para a execução das atividades planejadas.

Esta distinção está também presente na organização policial civil, consistindo, fundamentalmente, na divisão que separa hierarquicamente as funções, competências e atribuições funcionais relacionadas às atividades de planejamento conferidas aos Delegados de Polícia e aquelas designadas às atividades de execução atribuídas aos Agentes Policiais. No entanto, uma observação empírica, ainda que superficial, indica que, na organização policial civil, esta separação não se traduz com a mesma força e intensidade como no interior da organização policial militar, que mantém uma rígida hierarquia e disciplina no ambiente organizacional da corporação.

O exame dos currículos dos centros de ensino e treinamento profissional básico das duas corporações revela que: por um lado, há entre as polícias, uma grande variação no conteúdo das disciplinas dos cursos, estrutura e extensão dos programas de treinamento básico policial; por outro lado, não há muita diferenciação no conteúdo simbólico do "fazer profissional" do policial, reforçando a reprodução do "modelo policial profissional tradicional" no processo de formação do futuro policial em ambas as corporações.

A predominância do "modelo policial profissional tradicional" no conteúdo do processo de formação profissional do futuro policial encontra-se consubstanciado em uma concepção do trabalho policial que enfatiza o comportamento legalista dos policiais em um arranjo burocrático-militar que influencia a cultura, a filosofia de trabalho, a política administrativa, o treinamento, as operações, táticas e estratégias policiais.

Nesta perspectiva, pode-se inferir que a concepção presente nos currículos acerca do trabalho policial - civil e militar - baseia-se essencialmente no controle do crime e na aplicação da lei, com ênfase na importância de sua adesão a regras e procedimentos da organização, negligenciando o enfoque da interação com o cidadão através da negociação de conflitos para o desenvolvimento das tarefas relacionadas à manutenção da ordem, que são demandadas 
cotidianamente à polícia, e que são desconsideradas, na sua quase totalidade, nos conteúdos programáticos dos cursos em questão.

Portanto, no que diz respeito ao "fazer profissional", evidenciase a dificuldade dos cursos de formação profissional básica em abranger a amplitude das atribuições da polícia relacionada à realidade complexa e contingente do trabalho policial para a manutenção da ordem, prevenção e repressão do crime na sociedade.

Há que ressaltar, ainda, que somada às deficiências de preparo nos cursos de formação profissional básica em ambas as organizações, observa-se a falta de regularidade para a realização dos cursos para o aprimoramento profissional ao longo da carreira do policial. ${ }^{10}$

Vale a pena destacar, igualmente, que esses cursos não alcançam a totalidade dos membros das referidas corporações, pois privilegiam em sua quase totalidade os postos de comando ou direção, alcançando de forma muito incipiente os postos hierárquicos inferiores das organizações policiais. ${ }^{11}$

Acrescente-se, também, que tanto a Polícia Militar quanto a Polícia Civil não possuem um corpo de docentes inteiramente dedicado ao ensino. Os professores ${ }^{12}$ dos cursos de formação profissional básica, oferecidos por ambas organizações policiais são, majoritariamente, policiais advindos da própria Corporação, os quais, além de acumularem a atividade docente com outras atividades próprias ao cargo prioritariamente exercido na corporação, não possuem necessariamente uma formação pedagógica adaptada à função. Além disso, para os professores advindos da Corporação não há remuneração pelo desenvolvimento da atividade de ensino. Para esses policiais há, de fato, um acréscimo na sua carga horária de trabalho; objetivamente, o maior bônus para esses policiais é a pontuação para progressão na carreira. ${ }^{13}$

A análise dos currículos dos cursos de formação profissional da Polícia Civil do Estado do Rio de Janeiro (PCERJ) ${ }^{14}$ revela que a formação profissional básica das carreiras estudadas - agentes de policia estadual de investigação e prevenção criminais ${ }^{15} \mathrm{e}$ autoridade 
policial $^{16}$ - apresenta um certo equilíbrio entre os conteúdos programáticos e a carga horária dos cursos, predominando os diversos aspectos referentes às atribuições constitucionais da polícia judiciária, enfocando o conhecimento técnico básico do "fazer profissional" do policial civil, com forte ênfase no Direito Penal e nos procedimentos de rotina desenvolvidos nas Delegacias de Polícia.

Verifica-se, porém, a ausência de disciplinas voltadas para o preparo do policial na competência interpessoal, seja na relação interpares no ambiente organizacional, seja na interação com o público usuário das Delegacias de Polícia.

Pode-se inferir, portanto, que a formação profissional retratada nos currículos examinados demonstra uma concepção do trabalho policial numa perspectiva exclusivamente legalista, sugerindo que as atividades desenvolvidas pelo policial civil se restringem ao trato meramente técnico de execução plena da lei. Por conseguinte, tal como está organizada, essa formação negligencia a interação interpares e com o público como uma preocupação principal da prestação de serviço junto às diversas questões que emergem no cotidiano das Delegacias de Polícia.

A análise dos currículos dos diferentes cursos de formação profissional da Polícia Militar do Estado do Rio de Janeiro (PMERJ) evidencia, primeiramente, que há uma profunda variação na formação profissional básica dos policiais militares $-\operatorname{praças~}^{17}$ e oficiais ${ }^{18}-$ no que se refere aos conteúdos programáticos e à carga horária entre si, mantendo diferenças substanciais na concepção e no preparo dos indivíduos para exercerem a função policial, com uma distinção clara entre aquele que é preparado para o planejamento e aquele que é preparado para execução.

O exame realizado indica, ainda, por um lado, que esses cursos conferem ao futuro policial militar - praça e oficial - um perfil eminentemente dirigido para o policiamento geral ostensivo, com ênfase na preparação física do policial, sugerindo, assim, uma concepção de controle do crime, na qual são exigidas força física e virilidade, em detrimento de uma outra noção que enfoca a 
administração de conflitos e o relacionamento direto com o cidadão. Por outro lado, a análise aponta uma séria deficiência na área da atividade preventiva, com enfoque na negociação de conflitos e no relacionamento direto com o cidadão, retratada no baixo índice de disciplinas da área das ciências humanas e sociais no total da carga horária destinada às disciplinas curriculares do Curso.

Chama a atenção, também, a predominância da formação jurídica presente, principalmente, no currículo do Curso de Formação de Oficiais Policiais Militares, denotando uma noção da atividade policial que privilegia, de maneira acentuada, o uso da lei criminal para controle do crime, omitindo, em boa parte, a aplicação de conhecimentos e qualificação requeridos para a administração das variadas situações concernentes à manutenção da ordem, com relação às quais o policial precisa tomar constantemente decisões que escapam ao tratamento meramente jurídico, requerendo a aplicação de conhecimentos e habilidades relacionados às ciências humanas para o manejo adequado de conflitos diversos nas relações interpessoais.

Com respeito ao preparo profissional do policial militar para o desempenho das diferentes e conflitantes funções - função civil de policiamento e função militar de força auxiliar e reserva do Exército -, pode-se inferir que a presença das idéias e valores do militarismo na Polícia Militar do Estado do Rio de Janeiro (PMERJ) relaciona-se menos com a concepção militarizada sobre a missão da polícia e as estratégias operacionais utilizadas para a consecução de seus objetivos, referindo-se mais nitidamente à conservação da forma organizativa adotada pela corporação, rigidamente estruturada com base na hierarquia e na disciplina.

Neste sentido, ressalta-se a participação bastante limitada de disciplinas vinculadas ao ensino militar nos conteúdos programáticos dos currículos oficiais dos centros de formação e treinamento da PMERJ para o preparo do futuro policial.

Porém, se por um lado se observa a pouca participação das disciplinas de ensino militar nos cursos de formação profissional da 
Polícia Militar, pode-se verificar, por outro lado, que as disciplinas contidas nos diferentes currículos estão baseadas em uma concepção de segurança pública, segundo a qual o policiamento ostensivo está dirigido para o controle do crime, pela via do confronto, havendo necessidade de intervenções do "policial combatente" para a manutenção da ordem e repressão ao crime.

Verifica-se que a identificação com o militarismo pode ser encontrada mais acentuadamente no estilo de comportamento dos policiais militares, principalmente daqueles lotados nas unidades operacionais especiais da Corporação, como o Batalhão de Operações Especiais (BOPE), mas é também claramente identificável no estilo de comportamento dos policiais militares que fazem o policiamento ostensivo nas ruas, em luta na "guerra contra o crime". Entretanto, de maneira análoga, esse estilo de comportamento pode ser encontrado nos policiais civis lotados nas unidades especializadas da corporação, como, por exemplo, a Coordenadoria de Recursos Especiais (CORE), com estratégias de ação muito próximas às das unidades operacionais especiais da Polícia Militar, o que pode ser identificado na chamada "tiragem", cuja atividade compreende também o "trabalho de rua". Note-se, ainda, que os discursos e atitudes relacionados à "guerra contra o crime" podem ser identificados, igualmente entre os policiais lotados nas atividades internas das Delegacias Policiais distritais e dos quartéis da Polícia Militar. $^{19}$

Observa-se, pois, a existência de uma importante dimensão do "mundo policial" - a dimensão cultural - que expressa as crenças, os preconceitos e os estereótipos produzidos no interior da organização policial, mas também fora dela, sobre a "missão" da polícia - o combate ao crime - manifestando-se no comportamento e atitudes do policial com relação às experiências concretas e diárias do seu trabalho.

Deste modo, a presença de idéias e valores do militarismo na organização policial deve ser buscada, principalmente, na cultura policial como parte expressiva do conjunto de crenças, valores, reflexões e modos pelos quais a polícia acomoda as exigências e 
demandas da burocracia policial e da sociedade, com vistas a garantir um desempenho "eficiente" da ação policial, em uma perspectiva que dá ênfase ao uso da força e da dominação como meios apropriados para resolver problemas de manutenção da ordem e segurança públicas. Pode-se argumentar que é forjado um padrão de comportamento que legitima simbolicamente o trabalho policial à vista de todos e afirma a identidade do policial como um "soldadoguerreiro", encorajando ações agressivas para fazer face à missão que lhe foi designada.

A formação do policial orientada fundamentalmente para o controle do crime, com forte apelo ao "combate ao crime", tem a grande vantagem de fornecer o que é percebido amplamente pelo público e pelos próprios policiais como a missão das instituições policiais. Nesta perspectiva, evidencia-se que o ethos guerreiro é paulatinamente sedimentado na identidade profissional do policial como um importante requisito para que o policial possa, "com sucesso", realizar a árdua missão do "combate real" à criminalidade.

Muito embora a reprodução da concepção do trabalho policial no "modelo policial profissional tradicional" não seja exclusiva da polícia brasileira, haja vista que, tradicionalmente, a polícia foi organizada dentro do modelo profissional "burocrático-militar" e permaneça em muitos países com este formato, o grau e tipo de ênfase militar e/ou legalista encontrada na polícia variam amplamente de país a país e, sob determinadas circunstâncias, dentro dos contextos nacionais particulares. Variações são observadas, na ênfase dada aos papéis de repressão e coerção, de prevenção de crime, de serviço social, ou de polícia política, refletindo modelos de representação do "mundo policial" e do "mundo social" relacionados às condições sócio-históricas em que a organização policial foi criada e se desenvolveu.

\section{Considerações finais}

A pesquisa realizada nos centros de ensino e treinamento profissional da Polícia Civil e da Polícia Militar do Estado do Rio de 
Janeiro revela a permanência do denominado "modelo profissional policial tradicional", no conteúdo do processo formal de socialização profissional do futuro policial consubstanciado em uma concepção do trabalho policial profissional que enfatiza o comportamento legalista dos policiais em um arranjo burocrático-militar que influencia a cultura, a filosofia de trabalho, a política administrativa, o treinamento, as operações, táticas e estratégias policiais.

Os currículos dos cursos de formação profissional para os futuros policiais revelam uma ênfase excessiva no controle do crime em uma estratégia exclusivamente reativa da polícia, e dirigida principalmente para o confronto, apontando deficiências na área da atividade preventiva, com enfoque na negociação de conflitos e no relacionamento direto com o cidadão; evidencia-se, igualmente, uma clara negligência no preparo do policial - civil e militar - para o trato de outras demandas e interesses da população que não estejam restritas apenas ao cumprimento de lei, mas que dizem respeito à manutenção de ordem pública pela via da negociação.

Merece destaque, além das deficiências de preparo nos cursos de formação profissional básica para as diferentes carreiras na Polícia Civil e na Polícia Militar, a falta de regularidade para a realização dos cursos para o aprimoramento profissional ao longo da carreira do policial.

Apesar de, no Brasil, e particularmente no Rio de Janeiro, terem sido realizadas algumas experiências, ao longo das duas últimas décadas, na área de formação profissional da polícia, não foi ainda consolidada uma ampla agenda de reformas para a área de segurança pública e, em especial, um projeto educacional que propicie não somente resultados palpáveis em face das demandas para uma política de policiamento, mas também que coloque em obra valores que satisfaçam interesses de longo e duradouro espectro institucional e societário, vinculados a um modelo de polícia profissional de tipo "novo". 
No caso brasileiro, pode-se constatar que, até o momento, não houve um amplo e sistemático debate sobre a "profissão" policial, nem, tampouco, sobre modelos profissionais que possam nortear uma nova concepção do "fazer policial" para o desempenho mais eficaz, mais responsável e mais efetivo na condução da ordem e segurança públicas no contexto da sociedade brasileira contemporânea. Freqüentemente, as propostas para reformar a polícia têm sobreposto princípios de modelos profissionais, por vezes incompatíveis entre si, sem que se tenha uma extensa e profunda análise das condições internas e externas para a superação do modelo profissional em vigor e para a implementação bem-sucedida de um novo modelo de polícia profissional.

Verifica-se a aproximação ao "modelo de polícia profissional novo" somente em meados da última década, em alguns Estados da Federação, com ênfases diferenciadas e com uma certa fragilidade na consecução de mudanças na organização e no funcionamento da polícia. ${ }^{20}$

A pesquisa realizada nos centros de ensino e treinamento das polícias civil e militar indica o caráter descontínuo e fragmentário das propostas para a reforma da polícia e, especialmente, para a formação profissional do policial, orientada em grande parte pela urgência de respostas imediatas às demandas e pressões para maior segurança.

A formação profissional de policiais civis e militares "cariocas" retrata um somatório de atos pontuais, isoladamente considerados, traduzindo-se em resultados imediatos que visam atender a uma determinada demanda pública, diferentemente dos atos que fundam as políticas públicas que buscam não apenas atingir objetivos e produzir resultados palpáveis, mas colocar em ação valores e satisfazer interesses mais amplos, de longo e duradouro espectro para a sociedade. $^{21}$

Neste sentido, pode-se inferir que, até o momento, as academias de polícia não contam com a provisão das ferramentas necessárias - 
recursos humanos e materiais - para a adoção de novas e diferentes estratégias que produzam uma mudança e mobilidade para o grupo ocupacional como um todo, em direção a um profissionalismo de tipo "novo", que possa nortear uma nova concepção do "fazer policial" para um desempenho mais eficaz, mais responsável e mais efetivo na condução da ordem e segurança públicas no contexto da sociedade brasileira contemporânea.

A formação profissional desenvolvida nas academias de polícia examinadas, encontra-se premida pelas demandas para dar respostas imediatas contra o crime e baseada em um determinado modelo profissional de polícia que reforça a identidade policial com uma cultura de controle do crime associada a convicções, valores e práticas que repousam no "combate", tem renovado os "velhos" princípios básicos do "fazer" policial, em contraste a um novo profissionalismo difundido em grande parte do mundo ocidental, em que o serviço público, o alto nível de educação policial e a busca de uma relação mais estreita entre a polícia e a comunidade são dimensões consideradas fundamentais para a construção de uma nova identidade profissional do policial afinada com as exigências do mundo contemporâneo.

\section{Notas}

1 Originalmente preparado para apresentação no GT: Violência, Criminalidade e Segurança, do XII Congresso Brasileiro de Sociologia, realizado em Belo Horizonte (MG), de 31 de maio a 3 de junho de 2005. Nesta versão, introduzi modificações.

2 Nesta perspectiva, vale a pena salientar o esforço que o Instituto de Segurança Pública - RIOSEGURANÇA, da Secretaria de Estado de Segurança Pública do Estado do Rio de Janeiro, vem fazendo no sentido de implementar dentro da política estadual de segurança pública, um programa de formação profissional para policiais. Com base na proposta para educação policial proveniente do documento sobre as diretrizes curriculares para a formação dos profissionais da área de segurança disponibilizado pela Secretaria Nacional de Segurança Pública (SENASP) o Instituto de Segurança Pública elaborou o "Currículo Integrado de 
Formação Policial do Estado do Rio de Janeiro", com vistas a compatibilizar os currículos da Academia de Polícia Civil e das Escolas da Polícia Militar formadoras de Delegados de Polícia e Oficiais da Polícia Militar, e demais integrantes das carreiras.

3 No caso da Polícia Civil, esta segunda etapa da socialização se dá privilegiadamente nas delegacias de polícia, e no caso da Polícia Militar nas unidades operacionais da corporação, notadamente nas ruas das cidades.

4 Fielding (1996) dá especial destaque ao fracasso deste tipo de abordagem em pelo menos duas áreas em que a polícia não pode contar com a sensibilidade pública: os crimes contra as mulheres, particularmente o manejo de investigações de estupro e de violência doméstica, e as agressões com motivações raciais.

5 Várias são as consequiências desse modelo policial profissional seja do ponto de vista do lugar do policial na organização, seja em termos da relação da polícia com o público. Neste texto privilegiou-se a análise das conseqüências desse modelo profissional na formação profissional do futuro policial. Outros aspectos como o isolamento da organização policial, o não-reconhecimento oficial do trabalho policial desenvolvido no exercício das atividades cotidianas em atendimento a situações que não se limitam ao âmbito criminal, entre outras foram abordadas no artigo que elaborei, intitulado $\mathrm{O}$ modelo de polícia profissional e a formação do futuro policial: um debate necessário na sociedade brasileira contemporânea, submetido, em abril de 2005, à Revista Brasileira de Ciências Sociais para publicação.

6 Na literatura estrangeira, consultar a propósito: Skolnick (1966), Reiss (1971), Manning (1977), Black (1980), Cain (1992), Reiner (1992), Bayley (1994) e Wilson (1994). Na literatura nacional consultar a respeito, Kant de Lima (1994), Mota (1995) e Muniz (1999).

7 Vários estudos empíricos apontam a "desilusão" do policial ao defrontar o conhecimento fornecido pela Academia sobre o trabalho policial e a prática cotidiana do trabalho policial. Ver a respeito: Reiner (1992), Cordner (1978), Chan (1999, 2001).

8 Vale ressaltar que, não obstante a análise aqui apresentada esteja referida à formação profissional do policial desenvolvida pelos centros de ensino e treinamento do estado do Rio de Janeiro, uma breve investigação junto aos programas dos cursos de formação profissional de diversas academias de polícia em diferentes Estados da Federação permite inferir 
que o modelo policial profissional "tradicional" é amplamente adotado para a formação do futuro policial, não se constituindo, portanto, uma peculiaridade exclusiva da polícia do Estado do Rio de Janeiro, repetindose, com poucas exceções, em todos os Estados do País.

9 Trata-se da pesquisa desenvolvida para a realização de minha tese de doutorado, Tornar-se policial: a construção da identidade profissional do policial no Estado do Rio de Janeiro, apresentada ao Departamento de Sociologia da Faculdade de Filosofia, Letras e Ciências Humanas da Universidade de São Paulo, em março de 2004.

10 Muito embora a mobilidade dentro da carreira policial, civil e militar, esteja sujeita à realização de cursos de aperfeiçoamento profissional, esses cursos nem sempre são oferecidos por razões diversas. Neste quadro, constitui-se exceção, o "Curso de Formação e Atualização do Programa Delegacia Legal", que é realizado regularmente para as diferentes carreiras da Polícia Civil pelo Grupo Executivo do Programa Delegacia Legal. Na Polícia Militar há uma maior regularidade na oferta de cursos de aperfeiçoamento, mas o público-alvo é constituído em grande parte por policiais que ocupam postos de comando ou direção na corporação.

11 Ver a propósito, Sapori (2002).

12 Apesar de, na Polícia Militar, ser usado o termo "instrutor" para designar o professor de uma disciplina, quando nos referirmos às duas corporações utilizaremos preferencialmente o termo "professor".

13 Na ocasião da realização de minha pesquisa de campo para a tese de doutorado havia na Polícia Civil uma remuneração, custeada pela Fundação de Apoio ao Ensino, Pesquisa e Desenvolvimento da Polícia Civil (FAEPOL), para os policias civis que desenvolviam também a atividade de ensino. Na Polícia Militar, não havia nenhuma remuneração para os policiais da ativa que exerciam também a atividade de ensino nos centros de ensino e treinamento profissional da Corporação.

14 Trata-se especialmente do "Curso de Formação Profissional para Inspetor de Polícia de 6 a Classe" e o "Curso de Formação e Orientação Profissional para o Cargo de Delegado de Polícia de $3^{\text {a }}$ Classe", do Quadro Permanente da Polícia Civil do Estado do Rio de Janeiro.

15 A classe de "agentes de policia estadual de investigação e prevenção criminais" compreende as carreiras de Inspetor de Polícia, Oficial de 
Cartório Policial e Investigador Policial (Quadro Permanente da Polícia Civil do Estado do Rio de Janeiro).

16 A classe de "autoridade policial" á composta pela carreira de Delegado de Polícia (Quadro Permanente da Polícia Civil do Estado do Rio de Janeiro).

17 A carreira de "praças" corresponde às graduações de soldado, cabo, sargento e subtenente (Quadro Permanente da Polícia Militar do Estado do Rio de Janeiro).

18 A carreira de "oficiais" reúne os postos de capitão, major, tenente-coronel e coronel (Quadro Permanente da Polícia Militar do Estado do Rio de Janeiro).

19 Ver a respeito, Poncioni (2004).

20 Nesta perspectiva, destaca-se a implementação de diferentes programas de policiamento envolvendo a Polícia Militar, entre os quais, o programa baseado em policiamento comunitário, desenvolvido na década de 90 em algumas cidades do Brasil, tais como: a "polícia-cidadã" na Bahia, a "polícia-comunitária" em Sergipe, a "polícia-interativa" no Espírito Santo. No Rio de Janeiro, em particular, duas experiências podem ser destacadas: o programa de policiamento comunitário da Polícia Militar e o Programa Delegacia Legal, envolvendo policiais civis, que sugere um outro "desenho" relacionado à concepção física e à forma de operação do trabalho policial tradicional em delegacias de polícia.

21 Vale a pena ressaltar, mais uma vez, que apesar de se reconhecer que há diferenças entre os Estados da Federação no que diz respeito à área de segurança pública, as fragilidades no processo de formação profissional do policial civil e militar apontadas acima não são exclusivas da polícia carioca.

Abstract: The Professional Police Model and the Professional Formation of the Future Policemen in the Police Academies of Rio de Janeiro State

In Brazil, an exam of the public security question reveals that, at least since the 1970s, there is a continuous growth of criminality and violence, mainly in the metropolitan and peripherial areas of great cities of the country, and that the judiciary system, and, in particular, the police has been ineffectual at facing this subject. In this scenery, one of the topics frequently pointed out by public security specialists, 
by public policy makers, by government authorities and even by the policemen/women is the necessity to professionalize the Brazilian police as a resource to qualify the force in a more efficient, responsible and effective way to maintain order and public security. The main goal of this work is to analyze the professional police model present in professional training developed in police academies - civil and military - and its consequences to the future policeman/woman formation to perform police daily activities. The analysis of the professional police formation is based on curricula accomplished by Police Academies in Rio de Janeiro state, administered by Academia Estadual Sylvio Terra (ACADEPOL), in which formation and specialization courses are carried out in order to provide professional improvement by Centro de Formação e Aperfeiçoamento de Praças 31 de Voluntários (CFAP), responsible for the formation and professional development of the police force; and by Academia de Polícia D. João VI (APM D. João VI), in which police command courses are offered.

Key words: police, professionalism, democracy, crime, violence.

\section{Referências bibliográficas}

ADORNO, Sergio; PERALVA, Angelina. Estratégias de intervenção policial no Estado contemporâneo. Tempo Social, Revista de Sociologia da USP, São Paulo, v. 9, n. 1, p. 1-4, maio, 1997.

AUTEN, J. H. The paramilitary model of police and police professionalism. In: BLACK, Donald.. The manners and customs of police. New York: Academic Press, 1980.

BLUMBERG, Abraham S.; NIEDERHOFFER, Elaine. The ambivalent force: perspectives on the police. $3^{\text {rd }}$ ed. New York: Holt, Rinehart and Winston, Third Edition, 1985, p. 122-132.

BAYLEY, David H. Police for the future, New York: Oxford: University Press, 1994.

BITTNER, Egon. The functions of the police in modern society: a review of background factors, current practices and possible role models, Crime and Delinquency Issues: A monograph series, DHEW Publication No (HSM) 72-9103, USA, 1972. 
BRETAS, Marcos Luiz; PONCIONI, Paula. A cultura policial e o policial carioca. In: PANDOLFI et al. (Orgs.). Cidadania, justiça e violência Rio de Janeiro: Editora Fundação Getulio Vargas, 1999. p.149-163.

CAIN, Maureen. Trends in sociology of police work. In: McCORMICK, Kevin R. E.; VISANO, Livy. Understanding police. Toronto: University of Toronto Press, 1992. p. 3-32.

CANO, Ignácio. Letalidade da ação policial no Rio de Janeiro. Rio de Janeiro: ISER, 1997.

CARTER, David L. The state of police education: policy direction for the $21^{\text {st }}$ century. Washington, D.C.: Police Executive Research Forum, 1989.

CHAN, Janet B. L.Negotiating the field: new observations on the making of police culture. Australian and New Zealand Journal of Criminology, v. 34, n. 2, p. 114-133, Aug. 2001.

CORDNER, W. Open and closed models of police organizations: tradition, dilemmas, and practical consideration. Journal of Police Science and Administration, n. 6, p. 22-34, 1978.

DRUMMOND, Douglas S.. Introduction. In: Police culture. Beverly Hills, Calif.: Sage Publication, 1976. p. 5-45.

FAIRCHILD, Erika S. Demilitarization of police forces: the case of the federal republic of Germany. Police Studies, The International Review of Police Development, v. 7, n. 4, p. 189-199, 1984.

FIELDING, Nigel. Enforcement, service and community models of policing. In: SAULSBURY, Wilson; MOTT, Joy; NEWBURN, Tim (Eds.). Themes in contemporary policing. London: Independent Committee of Inquiry into Role and Responsabilities of the Police, 1996. p. 4259.

GAROTINHO, Anthony; com Luiz Eduardo Soares, Barbara M. Soares, João Trajano Sento-Sé, Leonarda Musuneci e Silvia Ramos. Violência e criminalidade no Estado do Rio de Janeiro: diagnóstico e propostas para uma política democrática de segurança pública, Rio de Janeiro: Editora Hama, 1998.

HARRIS, R. N. The police academy: an inside view. New York: John Wiley, 1973.

KANT DE LIMA, Roberto [Relator] (com a colaboração de Jorge da Silva). Formação Policial. In: MJ - Secretaria Nacional dos Direitos Humanos. Grupo de Trabalho para avaliar a Segurança Pública no Brasil, Niterói, 17 de julho de 1997. 
KELLING, George L.; MOORE, Mark H. From political to reform to community: the evolving strategy of policing. In: GREENE, J. R.; MASTROFSKI, S. D. (Eds.). Community policing: rhetoric or reality. New York: Praeger Publishers, 1991. p.3-25.

LÉVY, René. A crise do sistema policial francês hoje: da inserção local aos riscos europeus. Tempo Social, Revista de Sociologia da USP, São Paulo, v. 9, n. 1, p.53-77, maio, 1997.

MANNING, Peter. Police work: the social organization of policing. Cambridge, MA: The MIT Press, 1977.

MOORE, Mark. H. Problem solving and community policing. In: TONRY, Michael; MORRIS, Norval (Eds.). Modern policing. Chicago: The University of Chicago Press, 1992.

MOTA, Paula Poncioni. A polícia e os pobres: representações e práticas em delegacias de polícia do Rio de Janeiro. 1995. Dissertação (Mestrado) - Escola de Serviço Social, Universidade Federal do Rio de Janeiro, 1995.

MUNIZ, Jaqueline; LARVIE, Sean Patrick; MUSUMECI, Leonarda; FREIRE, Bianca. Resistências e dificuldades de um programa de policiamento comunitário. Tempo Social, Revista de Sociologia da USP, São Paulo, v. 9, n. 1, p. 197-213, maio, 1997.

PONCIONI, Paula. Tornar-se policial: a construção da identidade profissional do policial no Estado do Rio de Janeiro. 2004. Tese (Doutorado) - Departamento de Sociologia, Faculdade de Filosofia, Letras e Ciências Humanas, Universidade de São Paulo. 2004.

REINER, Robert. The politics of the police. $2^{\text {nd }}$ ed. London: Harvester Wheatsheaf, 1992.

. Police Research. In: KING, Roy D.; WINCUP, Emma (Eds). Doing research on crime and justice. Oxford University Press, 2000. p. 205-235.

REISS Jr., Albert J. The police and the public. New Haven: Yale University Press, 1971.

SAPORI, Luis Flávio. O treinamento como ferramenta de reforma policial na sociedade brasileira: perspectivas e limitações. Paper apresentado no Seminário Interpretações da Violência Urbana no Brasil, Rio de Janeiro, Universidade Federal do Rio de Janeiro, 2002. 
SCHAFFEL, Sarita Léa. A formação profissional de professores: um tema e muitas questões. O Social em Questão, Revista do Programa de Pós-Graduação em Serviço Social da PUC-RJ, Rio de Janeiro, v. 5, n. 5, p. 79-101, 2000.

SKOLNICK, Jerome H. Justice without trial: law enforcement in democratic society. New York: MacMillan, 1966.

STINCHCOMBE, Jeanne B. Beyond bureaucracy: a reconsideration of the 'professional' police. Police Studies: The International Review of Police Development, v. 3, n. 1, p. 49-61, 1980.

VAN MAANEN, John. On the making of policemen. In: KLOCKARS, C. B. Thinking about police: contemporary readings. $2^{\text {nd }}$ ed. New York: McGraw-Hill, 1983. p. 388-400.

. Processando as pessoas: estratégias de socialização organizacional. In: FLEURY, Maria Teresa L. et al. Cultura e poder nas organizações. São Paulo: Atlas, 1989. p. 45-62.

WILSON, James. Variedades do comportamento policial: a administração da lei e da ordem em oito comunidades. Rio de Janeiro: Polícia Militar do Estado do Rio de Janeiro, 1994. 